\title{
A method to dynamically constrain black carbon aerosol sources with online monitored potassium
}

\author{
Huang Zheng $\mathbb{1}^{1,2}$, Shaofei Kong $\mathbb{1}^{1,2,3 凶}$, Nan Chen ${ }^{3,4}$, Zewei Fan ${ }^{1}$, Ying Zhang ${ }^{1}$, Liquan Yao ${ }^{1,2}$, Yi Cheng ${ }^{1,2}$, Shurui Zheng ${ }^{1,2}$, \\ Yingying Yan ${ }^{1}$, Dantong $\mathrm{Liu}^{5}$, Delong Zhao ${ }^{6}$, Chao Liu', Tianliang Zhao ${ }^{7}$, Jianping Guo $\mathbb{1}^{8}$ and Shihua $\mathrm{Qi}^{2}$
}

The result of Aethalometer model to black carbon $(\mathrm{BC})$ source apportionment is highly determined by the absorption Ångström exponent $(a)$ of aerosols from fossil fuel combustion $\left(a_{\mathrm{ff}}\right)$ and wood burning $\left(a_{\mathrm{wb}}\right)$. A method using hourly measured potassium to calculate the $a_{\mathrm{ff}}$ and $a_{\mathrm{wb}}$ values was developed in this study. Results showed that the optimal $a_{\mathrm{ff}}$ and $a_{\mathrm{wb}}$ were 1.09 and 1.79 for the whole dataset. The optimal $a$ values in the diurnal resolution were also calculated with $a_{\mathrm{ff}}$ and $a_{\mathrm{wb}}$ varied in $1.02-1.19$ and 1.71-1.90, respectively. Using the dynamic $a$ values, the Pearson correlation coefficient between $B C$ and potassium from wood burning substantially improved compared to the results derived from the fixed a values. The method developed in this study is expected to provide more reasonable BC source identification results, which are helpful for air quality, climate, and human health modeling studies.

npj Climate and Atmospheric Science (2021)4:43; https://doi.org/10.1038/s41612-021-00200-y

\section{INTRODUCTION}

Black carbon (BC) is an important aerosol component and is primarily emitted from fossil fuel combustion and wood burning. BC has strong absorption of light from ultraviolet to near-infrared wavelengths ${ }^{1}$ and it contributes to global warming, following $\mathrm{CO}_{2}^{2-4}$. Adverse impacts of $\mathrm{BC}$ on regional air quality ${ }^{5,6}$ and human health ${ }^{7-9}$ have been widely reported. Considering its short atmospheric lifetime $\left(4-12\right.$ days) ${ }^{10-12}$, reducing $B C$ emissions would have synergistic benefits against its warming ${ }^{13}$, air pollution ${ }^{14}$, and adverse human health effects ${ }^{8,9}$. For reducing BC emissions, it is important to quantify the contributions of its various sources.

There are five methods to apportion the BC sources including receptor model, radiocarbon method, Marco-tracer, air quality modeling, and the Aethalometer method. The key strengths and weaknesses of these common BC source apportionment methods are summarized elsewhere ${ }^{15}$. Among these methods, the Aethalometer model has the advantages of high temporal resolution and is easy to be operated ${ }^{16}$. Therefore, it has been widely adopted in BC source apportionment studies ${ }^{16-22}$. This method uses the aerosol light absorption at two wavelengths to apportion the equivalent $B C(e B C)$ into fossil fuel combustion-related $e B C$ $\left(\mathrm{eBC}_{\mathrm{ff}}\right)$ and wood burning-related $\mathrm{eBC}\left(\mathrm{eBC}_{\mathrm{wb}}\right)^{16}$. The accuracy of the Aethalometer model results is mainly dependent on the absorption Ångström exponent $(a)$ for fossil fuel combustion $\left(a_{\mathrm{ff}}\right)$ and wood burning $\left(a_{\mathrm{wb}}\right)$. Previous studies always applied fixed $a$ values in the Aethalometer model ${ }^{17,22-27}$. However, $a_{\mathrm{ff}}$ and $a_{\mathrm{wb}}$ varied in the ranges of $0.9-1.1^{28,29}$ and $0.9-3.5^{30-32}$, respectively, determined by combustion efficiency ${ }^{33}$, mixing state of aerosol components ${ }^{33-35}$, aerosol size ${ }^{36}$, and chemical composition ${ }^{37}$. It is problematic to use fixed $a$ values in the Aethalometer model. Previous studies also showed spatial heterogeneity in the optimal combination of $a_{\mathrm{ff}}$ and $a_{\mathrm{wb}} \cdot a_{\mathrm{ff}}=0.90$ and $a_{\mathrm{wb}}=1.68$ were recommended in Switzerland ${ }^{38}$. $a_{\mathrm{ff}}=1.10$ and $a_{\mathrm{wb}}=1.60$ were adopted in Helsinki of Finland ${ }^{21}$. A combination of $a_{\mathrm{ff}}=0.90$ and $a_{\mathrm{wb}}=1.82$ was reported in metropolitan Milan, Italy ${ }^{39}$. The optimal $a_{\mathrm{ff}}$ and $a_{\mathrm{wb}}$ were reported in the ranges of $0.97-1.12$ and $1.63-1.74$, respectively, in the urban and rural areas of $\operatorname{Spain}^{40}$. Therefore, the determination of site-specific $a_{\mathrm{ff}}$ and $a_{\mathrm{wb}}$ is essential prior to using the Aethalometer model.

To get the site-specific $a_{\mathrm{ff}}$ and $a_{\mathrm{wb}}$, previous studies used auxiliary measurements such as radiocarbon $\left({ }^{14} C\right)^{16,38,39,41}$ and levoglucosan $(L G)^{20,21,40,42} \cdot{ }^{14} \mathrm{C}$ is an ideal tool to distinguish $B C$ from the combustion of contemporary carbon and fossil fuel ${ }^{43}$. The constraint using ${ }^{14} \mathrm{C}$ can precisely obtain the optimal $a_{\mathrm{ff}}$ and $a_{\mathrm{wb}}{ }^{38,39}$. The attribution using ${ }^{14} \mathrm{C}$ still has some issues such as sample contamination, improvement in instrument analysis, and the separation of organic carbon (OC) and elemental carbon $(E C)^{43}$. These issues inevitably introduce uncertainty to the source apportionment result. Constraint using the linear regression between LG and $\mathrm{eBC}_{\mathrm{wb}}$ can calculate the optimal $a_{\mathrm{ff}}$, while the optimal $a_{w b}$ value is empirically chosen. The usage of LG to get the optimal a combination also has shortages. LG undergoes chemical degradation from the source to receptor ${ }^{44-46}$ and it has other sources such as coal combustion ${ }^{47,48}$, cooking emission ${ }^{49}$, and garbage burning ${ }^{50}$, etc. These sources would result in an overestimated contribution of wood burning to BC. Additionally, previous studies with ${ }^{14} \mathrm{C}$ or LG to find the optimal $a$ values were low in temporal resolution, which was determined by the sampling duration (i.e., $>23 \mathrm{~h})^{51}$. However, the BC emission sources showed obvious diurnal variations, which suggested that the previous studies with the ${ }^{14} \mathrm{C}$ and LG constraints failed to describe the dynamic variations of optimal $a$ values within a day. Therefore, a wood burning tracer with properties of chemical

\footnotetext{
${ }^{1}$ Department of Atmospheric Sciences, School of Environmental Studies, China University of Geosciences (Wuhan), Wuhan, China. ${ }^{2}$ Department of Environmental Science and Engineering, School of Environmental Studies, China University of Geosciences (Wuhan), Wuhan, China. ${ }^{3}$ Research Centre for Complex Air Pollution of Hubei Province, Wuhan, China. ${ }^{4}$ Hubei Environmental Monitoring Centre, Wuhan, China. ${ }^{5}$ Department of Atmospheric Sciences, School of Earth Sciences, Zhejiang University, Hangzhou, China. ${ }^{6}$ Beijing Weather Modification Office, Beijing, China. ${ }^{7}$ Collaborative Innovation Centre on Forecast and Evaluation of Meteorological Disasters, Key Laboratory for Aerosol-CloudPrecipitation of China Meteorological Administration, Nanjing University of Information Science and Technology, Nanjing, China. ${ }^{8}$ State Key Laboratory of Severe Weather, Chinese Academy of Meteorological Sciences, Beijing, China. ${ }^{凶}$ email: kongshaofei@cug.edu.cn
} 
a

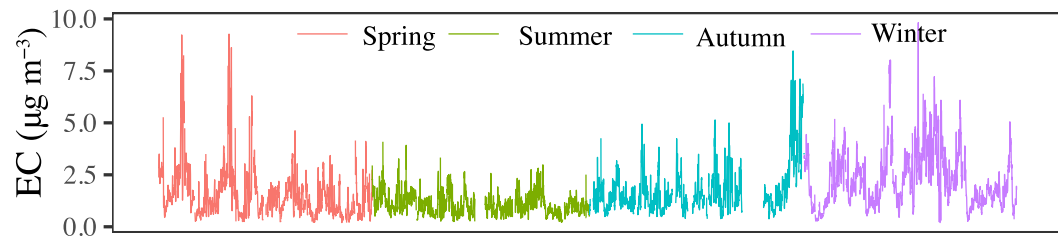

b

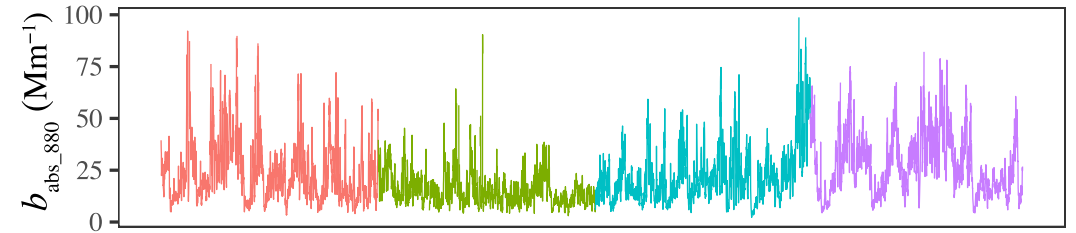

c

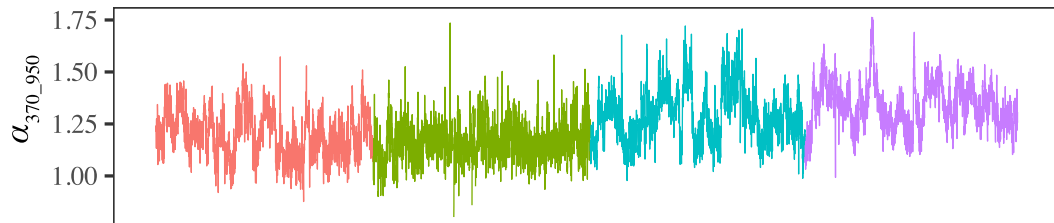

d

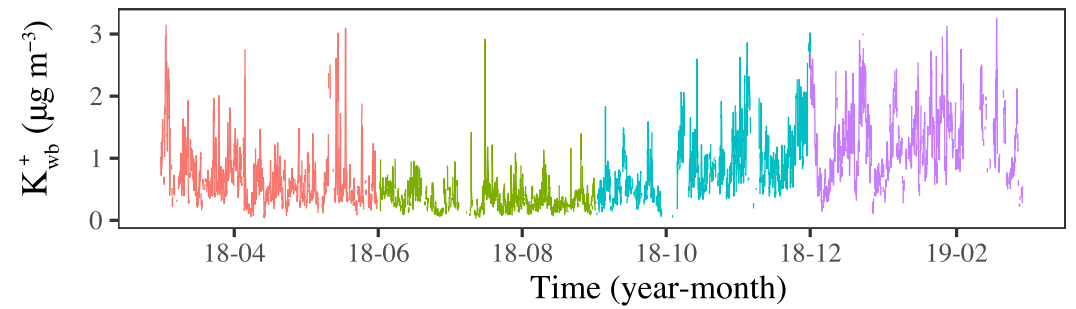

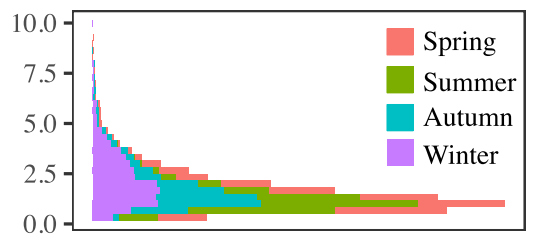
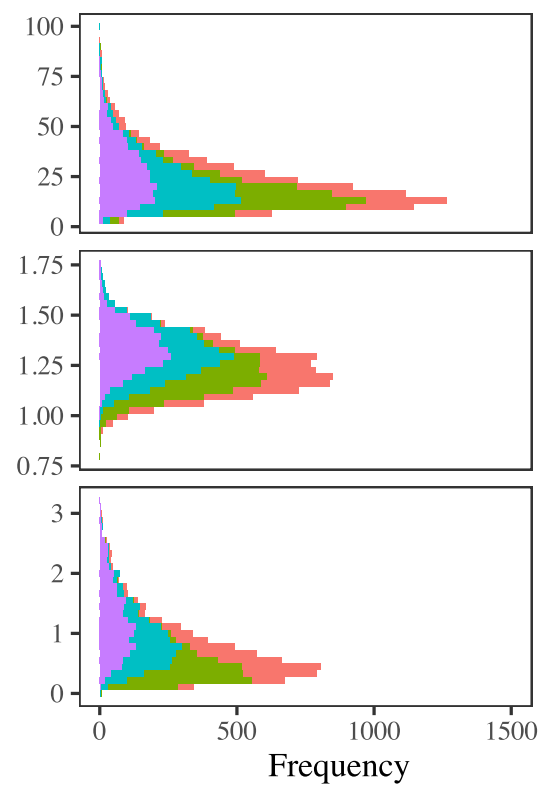

Fig. 1 Time series and distribution characteristics of key variables during the observational period. a Elemental carbon (EC). b Aerosol light absorption at $880 \mathrm{~nm}\left(b_{\text {abs_880 }}\right)$. c Absorption Ångström exponent was calculated by power-law fit at 7 wavelengths from 370 to $950 \mathrm{~nm}$ $\left(a_{370 \_950}\right)$. d Potassium from wood burning $\left(\mathrm{K}_{\mathrm{wb}}^{+}\right)$. The colors in the figures represent different seasons (Spring: March, April, and May; Summer: June, July, and August; Autumn: September, October, and November; Winter: December, January, and February).

inertness, high-temporal resolution, and easy to be measured is needed to optimize the $a$ values in the Aethalometer model ${ }^{38}$.

Potassium has been widely used as a tracer of wood smoke/ biomass burning ${ }^{52-54}$. Compared to the sample collection and chemical analysis of ${ }^{14} \mathrm{C}$ and LG, potassium has the advantage of high-temporal resolution (i.e., $1 \mathrm{~h}$ ) in measurement ${ }^{55,56}$. Despite the exitance of additional sources of potassium (sea salt and soil dust), the potassium from wood burning $\left(\mathrm{K}_{\mathrm{wb}}^{+}\right)$can be corrected ${ }^{19}$. The $\mathrm{K}_{\mathrm{wb}}^{+}$can be further used to optimize the $a$ values in the Aethalometer model. Currently, almost all the environmental monitoring supersites in China synchronously monitor the realtime potassium and BC with an online ion chromatography analyser and Aethalometer, respectively. Whether $\mathrm{K}_{\mathrm{wb}}^{+}$can be adopted to improve the hourly BC source apportionment results by the Aethalometer model has not been reported.

In this study, the method to calculate the $a_{\mathrm{ff}}$ and $a_{\mathrm{wb}}$ was first developed and then applied to calculate the optimal $a_{\mathrm{ff}}$ and $a_{\mathrm{wb}}$ values at hourly resolution. The BC source apportionment results using the fixed and dynamic constraining a values were compared. Finally, the uncertainty of this method was estimated.

\section{RESULTS}

\section{General characteristics}

Figure 1 shows the hourly variations and distribution characteristics of ambient $\mathrm{EC}, \mathrm{K}_{\mathrm{wb}}^{+}$, absorption coefficient at $880 \mathrm{~nm}$ $\left(b_{\text {abs_880 }}\right)$, and $a_{370 \_950}$ during the observational period. EC, $\mathrm{K}_{\mathrm{wb}}^{+}, b_{\mathrm{abs} 880}$, and $a_{370} 950$ varied in the ranges of $0.20-9.82 \mu \mathrm{g}$ $\mathrm{m}^{-3}, 0.03-3.25 \mathrm{\mu g} \mathrm{m}^{-3}, 2.27-98.7 \mathrm{Mm}^{-1}$, and $0.80-1.76$, respectively. The highest values mostly occurred in winter with the mean ( \pm standard deviation) values of $2.22 \pm 1.30 \mu \mathrm{g} \mathrm{m}^{-3}, 1.22 \pm$
$0.58 \mu \mathrm{g} \mathrm{m}^{-3}, 27.6 \pm 14.2 \mathrm{Mm}^{-1}$, and $1.34 \pm 0.11$ correspondingly. The lowest mean values were found in summer, as $1.09 \pm$ $0.50 \mu \mathrm{g} \mathrm{m}^{-3}, 0.36 \pm 0.22 \mathrm{~g} \mathrm{~m}^{-3}, 15.5 \pm 7.81 \mathrm{Mm}^{-1}$, and $1.16 \pm$ 0.09 , respectively, for $\mathrm{EC}, \mathrm{K}_{\mathrm{wb}}^{+}, b_{\mathrm{abs} \_880}$, and $a_{370 \_950}$.

Similar seasonal patterns of these variables were also reported elsewhere (Supplementary Table 1). For instance, higher ambient aerosol a was reported in winter compared to other seasons. A higher $a$ value is indicative of wood burning and a lower $a$ value implies fossil fuel combustion ${ }^{21,42}$. Aerosols from wood burning contain abundant light-absorbing organic compounds (known as brown carbon) such as humic-like substances and polycyclic aromatic hydrocarbons. These organic compounds can strongly enhance the light absorption at ultraviolet wavelengths compared to those in the near-infrared wavelengths, where $B C$ dominates the absorption ${ }^{57-59}$. Aerosols from fossil fuel combustion, however, contain a higher fraction of $B C$ than organic compounds ${ }^{16}$. As summarized in Supplementary Table 2, aerosol from wood burning generally has a higher a value compared to fossil fuel (coal and oil) combustion. It should be noted that if aerosol from fossil fuel combustion has the same or higher a value as wood burning, the Aethalometer model would overestimate the contribution of wood burning. Anyway, a higher a value in winter suggested a larger fraction of $B C$ from wood burning.

\section{Method of determining the optimal a combination}

As shown in Fig. 2a, the Pearson correlation coefficients between $\mathrm{K}_{\mathrm{wb}}^{+}$and $\mathrm{eBC} \mathrm{wb}_{\mathrm{wb}}$ did not vary with $a_{\mathrm{wb}}$ increasing while it decreased with the increase of $a_{\mathrm{ff}}$. It suggested that the relationship between $\mathrm{eBC}_{\mathrm{wb}}$ and $\mathrm{K}_{\mathrm{wb}}^{+}$was only determined by $a_{\mathrm{ff}}^{20,21,42}$. The slope also showed a reduction with the increase of $a_{\mathrm{ff}}$. A higher slope was 

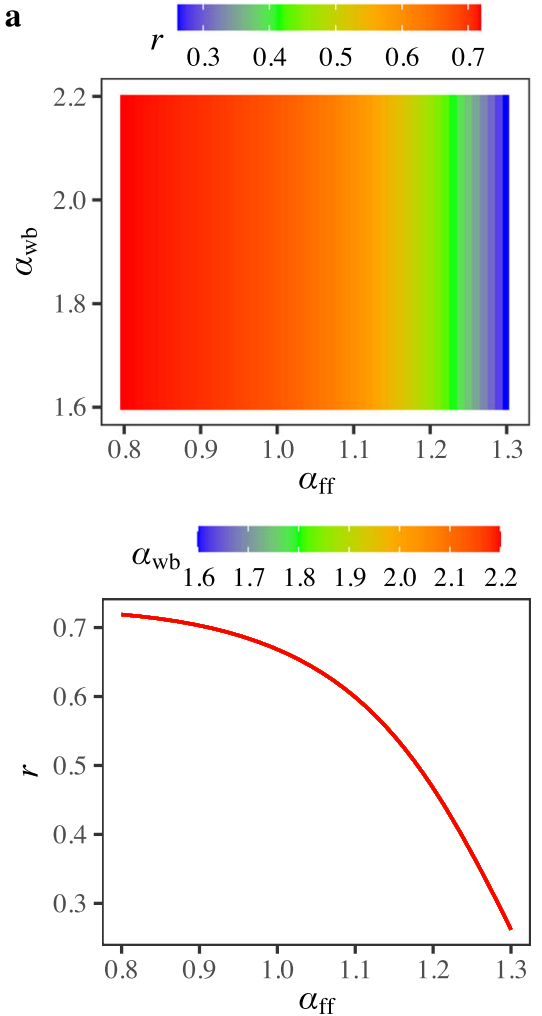

b
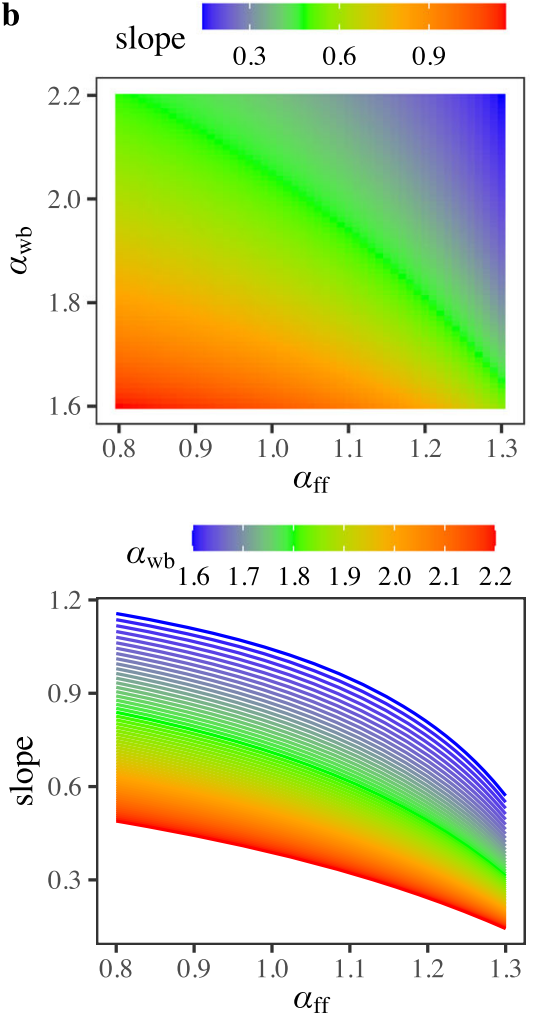
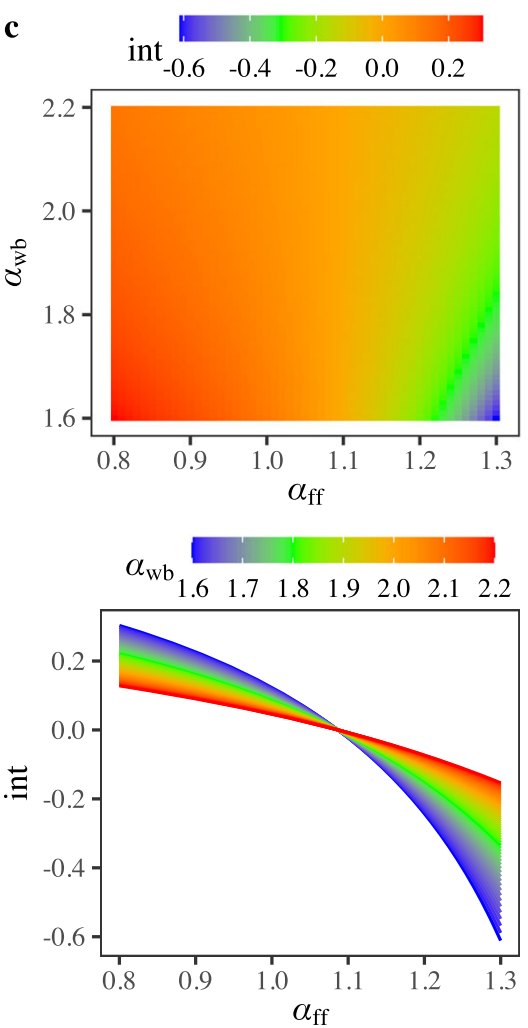

Fig. 2 Diagnostic parameters of linear regression equation as the function of different $\boldsymbol{a}$ combinations. a Pearson correlation coefficient (r). b Slope. c Intercept (int).

therefore found with a lower $a_{\mathrm{wb}}$ value if $a_{\mathrm{ff}}$ was fixed at a certain value (Fig. 2b). The intercept decreased with the increase of $a_{\mathrm{ff}}$ and the approximate zero value was only possible when the $a_{\mathrm{ff}}$ value was 1.09 (Fig. 2c). Therefore, $a_{\mathrm{ff}}=1.09$ was chosen as its physical meaning that $\mathrm{eBC}_{\mathrm{wb}}$ and $\mathrm{K}_{\mathrm{wb}}^{+}$were only from wood burning and they held similar atmospheric removal rates ${ }^{20,21,42}$.

To find the optimal $a_{\mathrm{wb}}$, previous studies determined it empirically according to the diurnal variations of $e B C_{w b}$ and $e B C_{f f}$ calculated with the optimal $a_{\mathrm{ff}}$ value and different $a_{\mathrm{wb}}$ values $^{21,42,60,61}$. The method failed to determine the optimal $a_{w b}$ in this study (Supplementary Fig. 1). As explained mathematically, the fixed variables except for $a_{\mathrm{wb}}$ in Eq. (5) can only result in the different values of $\mathrm{eBC}_{\mathrm{wb}}$. Only changing the $a_{\mathrm{wb}}$ in $\mathrm{eBC} C_{\mathrm{wb}}$ calculation in different hours within a day cannot modify the diurnal variations of eBC $C_{\mathrm{wb}}$. To determine the optimal $a_{\mathrm{wb}}$ value, the statistical parameters (NMB, RMSE, and IOA) for the linear regression between $e B C_{w b}$ and $\mathrm{K}_{\mathrm{wb}}^{+}$were used. The optimal statistical results of NMB, RMSW, and IOA were obtained when $a_{w b}$ were $1.60,1.79$, and 1.77 , respectively, at the optimal $a_{\mathrm{ff}}$ value (1.09) (Supplementary Fig. 2). To find the optimal $a_{\mathrm{wb}}$, the Taylor Diagram ${ }^{62}$ was further adopted to evaluate the model performances with different $a_{\mathrm{wb}}$ values (Fig. 3). The diagram showed how $r$, standard deviation, and RMSE varied simultaneously, which can be represented through the Law of Cosines ${ }^{63}$. The combination of $a_{\mathrm{ff}}=1.09$ and $a_{\mathrm{wb}}=1.79$ showed the lowest RMSE and the standard error, which was close to the observed standard deviation of $\mathrm{K}_{\mathrm{wb}}^{+}$. Therefore, $a_{\mathrm{wb}}=1.79$ was considered as the optimal value in this study.

The optimal $a_{\mathrm{ff}}$ value here (1.09) was higher than the optimal $a_{\mathrm{ff}}$ reported in Milan $(0.90)^{39}$ and London $(0.96)^{20}$ but was comparable with that in Granada $(1.10)^{42}$. Compared to the optimal $a_{\mathrm{wb}}$ of 1.68 in Switzerland ${ }^{38}$ and 1.82 in Milan $^{39}$, the optimal $a_{\mathrm{wb}}$ value here (1.79) was between them. The optimal

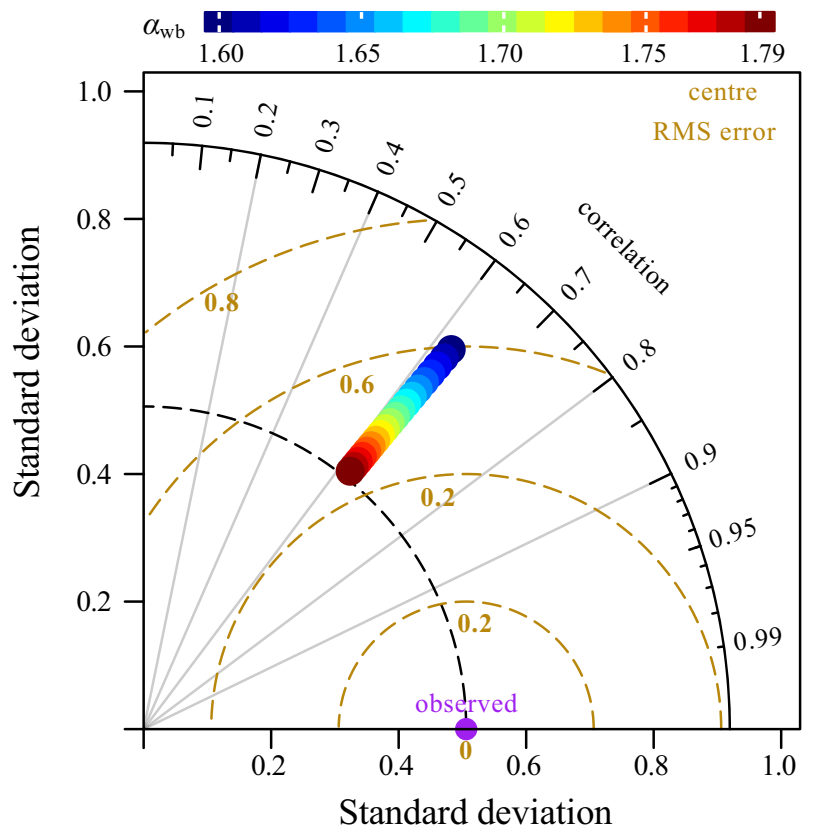

Fig. 3 Taylor diagram plot of different models. The models were built using the optimal $a_{\mathrm{ff}}$ value (1.09) and different $a_{\mathrm{wb}}$ values ranged from 1.60 to 1.79 with a 0.01 step.

$a_{\mathrm{wb}}$ value here was also within the reported values $(1.63 \pm 0.32)$ from smog chamber studies for fresh and aged wood burning emissions ${ }^{64}$, verifying that it was reasonable to use it in the Aethalometer model. 

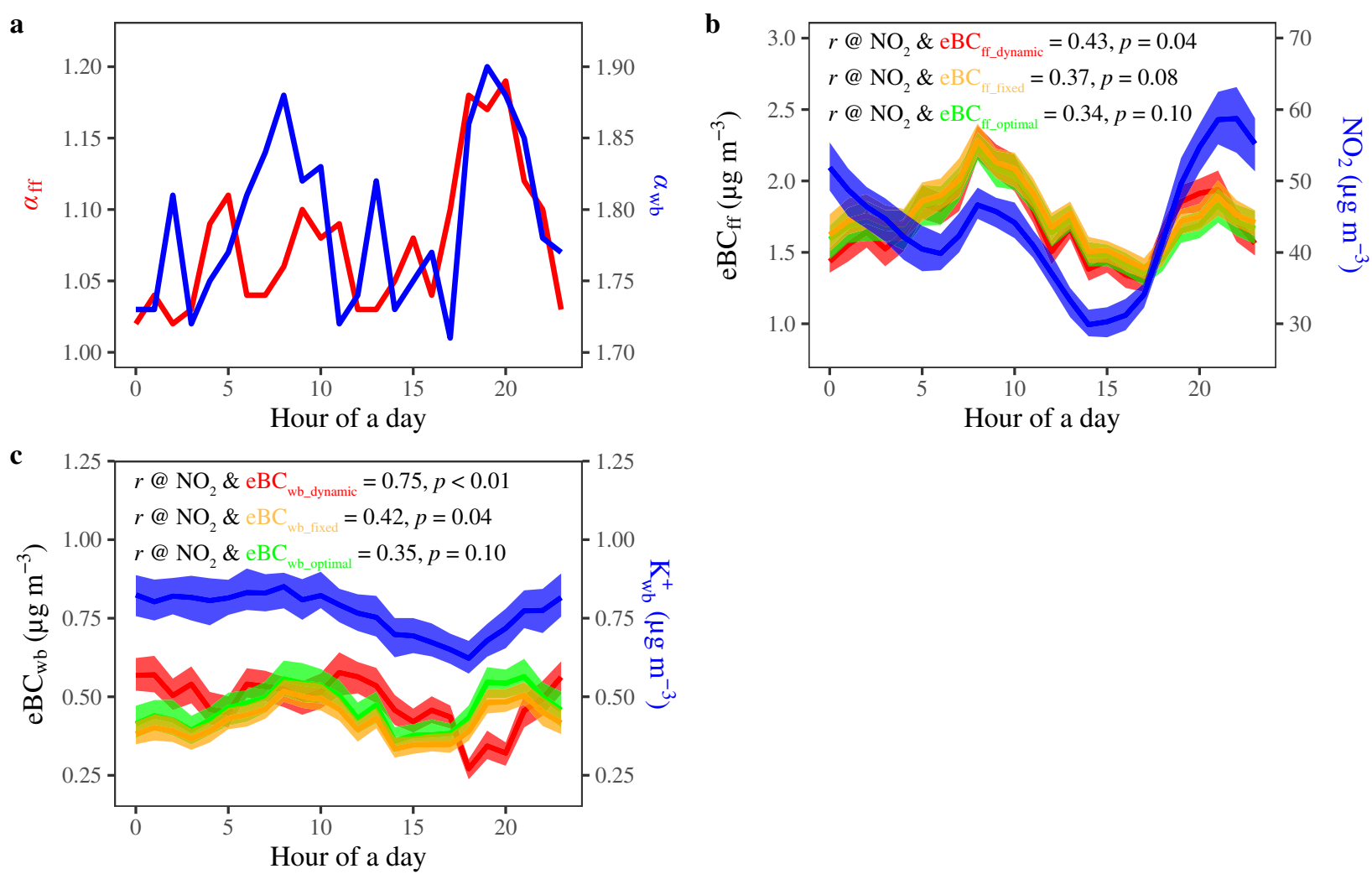

Fig. 4 Diurnal variations of optimal absorption Ångström exponent and black carbon source apportionment results. a Diurnal variations of optimal absorption Ångström exponent for aerosol from fossil fuel $\left(a_{\mathrm{ff}}\right)$ and wood burning $\left(a_{\mathrm{wb}}\right)$. b Diurnal variation of black carbon from fossil fuel $\left(\mathrm{eBC}_{\mathrm{ff}}\right)$. $\mathbf{c}$ Diurnal variation of black carbon from wood burning $\left(\mathrm{eBC} \mathrm{wb}_{\mathrm{w}}\right)$. The red, orange, and green lines in panel $\mathbf{b}$ and $\mathbf{c}$ represent the source apportionment results using the dynamic optimal (values in panel a), fixed $\left(a_{\mathrm{ff}}=1.0, a_{\mathrm{wb}}=2.0\right)$, and optimal $\left(a_{\mathrm{ff}}=1.0, a_{\mathrm{wb}}=1.79\right) a$ combinations, respectively. The filled areas in panels $\mathbf{b}$ and $\mathbf{c}$ represent the $95 \%$ confidence intervals of mean values.

\section{Constraining a combination at hourly resolution}

Following the method developed above, the optimal $a_{\mathrm{ff}}$ and $a_{\mathrm{wb}}$ were calculated at hourly resolution and they varied in the ranges of 1.02-1.19 and 1.71-1.90, respectively (Fig. 4a). To check the improvement of BC source apportionment results using the dynamic optimal $a$ values, the mass concentrations of $\mathrm{eBC}_{\mathrm{ff}}$ and $\mathrm{eBC}_{\mathrm{wb}}$ were calculated using both the fixed $a$ values $\left(a_{\mathrm{ff}}=1.0\right.$ and $\left.a_{\mathrm{wb}}=2.0\right)$, optimal $a$ values ( $a_{\mathrm{ff}}=1.09$ and $a_{\mathrm{wb}}=1.79$ ), and dynamic $a$ values. As shown in Fig. $4 \mathrm{~b}, \mathrm{eBC}$ ff calculated from the dynamic a combination significantly correlated with $\mathrm{NO}_{2}(r=$ $0.43, p=0.04)$, while their positive correlations calculated from the fixed and optimal $a$ values were not statistically significant $(p>$ 0.05). Additionally, the fraction of $\mathrm{eBC}_{\mathrm{ff}}$ calculated from the dynamic $a$ values clearly showed the increase during the morning and evening traffic rush. $\mathrm{eBC}_{\mathrm{ff}}$ fractions calculated from the fixed and optimal $a$ values decreased (Supplementary Fig. 3), which was not in accordance with the actual situation of enhanced vehicle emissions during the rush hours. For $\mathrm{eBC}_{\mathrm{wb}}$, the dynamic constraint also improved the reasonability of $B C$ source apportionment results. In Fig. $4 c$, the Pearson correlation coefficient between $\mathrm{eBC}_{\mathrm{wb}}$ and $\mathrm{K}_{\mathrm{wb}}^{+}$was $0.75(p<0.01)$ for the dynamic optimal $a$ values, which was higher than those calculated from the fixed $(r=0.42, p=0.04)$ and optimal $(r=0.35, p=0.10) a$ combinations. The diurnal variations in physical-chemical properties of aerosol (chemical composition, particle size, and source emission strengths) can be characterized by aerosol $a^{65}$. The increasing of optimal a combination from about 08:00 to 10:00 and from $16: 00$ to $20: 00$ in this study (Fig. 4a) suggesting that the dynamic $a$ values reflected the relative abundance of traffic and wood burning emissions. Therefore, BC source apportionment using the dynamic optimal a values showed more reasonable results compared to those calculated with fixed $a$ values.

BC source apportionment results and uncertainty estimation

The BC sources at an urban station of Wuhan, Central China were apportioned with the dynamic optimal a combinations. The temporal variations of $\mathrm{BC}$ sources are shown in Fig. 5 and Supplementary Fig. 4. $\mathrm{eBC}_{\mathrm{ff}}$ contributed to $77.5 \pm 18.9 \%$ of $\mathrm{eBC}$ with the highest contribution in summer $(90.5 \pm 9.81 \%)$ and lowest in winter (63.9 $\pm 17.6 \%)$. eBC $\mathrm{wb}_{\mathrm{wb}}$ accounted for $22.5 \pm 18.9 \%$ of eBC. Contrary to $\mathrm{eBC}_{\mathrm{ff}}$, the lowest percentage of $\mathrm{eBC}$ wb was found in summer $(9.52 \pm 9.81 \%)$ and the highest percentage occurred in winter $(36.1 \pm 17.6 \%)$. On the annual scale, $\mathrm{eBC}_{\mathrm{ff}}$ showed a positive correlation with ambient temperature $(r=0.11, p<0.05)$ while $\mathrm{eBC}_{\mathrm{wb}}$ was negatively correlated with ambient temperature $(r=$ $-0.51, p<0.01)$. $\mathrm{eBC}_{\mathrm{ff}}$ showed a significant positive correlation with $\mathrm{NO}_{2}(r=0.56, p<0.01)$ during the entire year, indicating that vehicle emission could be an important source of $\mathrm{BC}$ in urban areas $^{23,38,39}$. The high levels of $\mathrm{eBC}_{\mathrm{wb}}$ in winter and its negative correlation with ambient temperature suggested that more wood was consumed during winter for heating ${ }^{27}$. The diurnal variations of $\mathrm{BC}$ sources showed two peaks in the morning and evening due to the increased traffic emissions ${ }^{39,42}$. The minimum levels of eBC occurred in the afternoon, which was related to better dispersion conditions $^{61,66}$. eBC was negatively correlated with the mixing layer height and wind speed with Pearson correlation coefficients of $-0.38(p=0.06)$ and $-0.12(p=0.57)$, respectively. Therefore, the higher mixing layer height and larger horizontal wind speed in the afternoon contributed to the reduction of eBC levels ${ }^{61,66,67}$. 

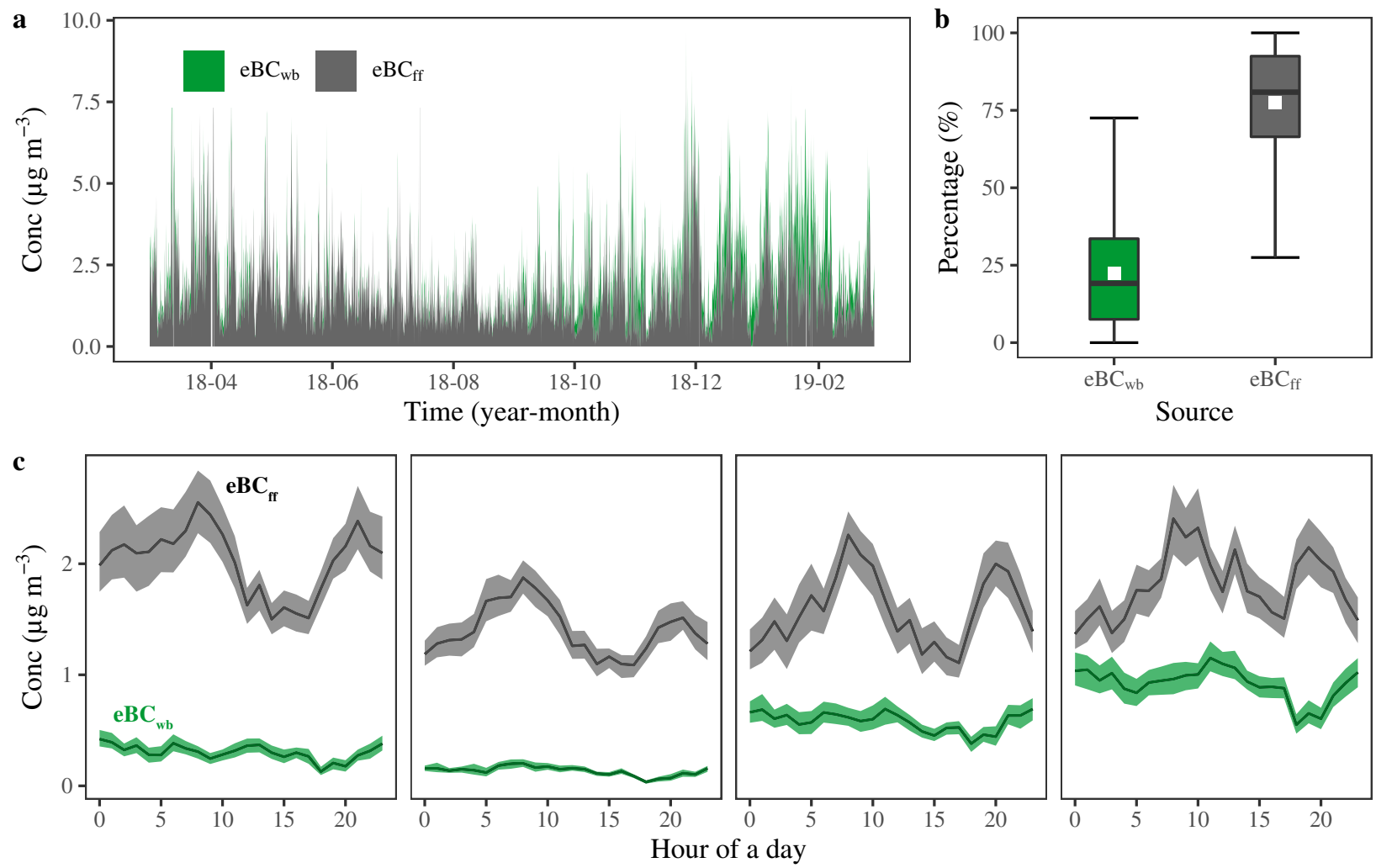

Fig. 5 BC source apportionment results using the dynamic absorption Ångström exponents. a Hourly variations of black carbon sources during the observational period. $\mathbf{b}$ Boxplot of their relative contributions to $B C$ mass concentration. $\mathbf{c}$ Diurnal variations of $B C$ sources in different seasons. The filled areas in panel c represent the $95 \%$ confidence intervals of mean values.

In this study, the uncertainties in the mass concentrations of $\mathrm{eBC}_{\mathrm{ff}}$ and $\mathrm{eBC} \mathrm{C}_{\mathrm{wb}}$ were estimated by the propagation of errors ${ }^{41}$. It should be noted that the uncertainties of $\mathrm{eBC}_{\mathrm{ff}}$ and $\mathrm{eBC} \mathrm{wb}_{\mathrm{wb}}$ in this study were associated with the measurement uncertainties rather than the true uncertainties of fossil fuel and wood burning derived $B C$ constrained by the radiocarbon method ${ }^{38}$. Several measurements including $b_{\mathrm{abs}}, \mathrm{EC}$, and $a$ would introduce uncertainties to the $B C$ source apportionment results. The absorption coefficients measured by $A E 31$ had an uncertainty of $5 \%{ }^{68}$. The uncertainty of OC/EC analyser was reported as $24 \%{ }^{69}$. $a_{\mathrm{ff}}$ and $a_{\mathrm{wb}}$ held the uncertainties of 4.63 and $3.32 \%$, respectively, estimated from the dynamic optimal $a$ values in this study. The uncertainty of MAC calculated from corrected $b_{\text {abs }}$ and EC was estimated as $24.5 \%$ which produced an uncertainty of $25.0 \%$ for $\mathrm{eBC}$ using the ratio of $b_{\mathrm{abs}}$ to MAC. Finally, the uncertainties of $\mathrm{eBC}_{\mathrm{ff}}$ and $\mathrm{eBC} \mathrm{cb}_{\mathrm{wb}}$ were estimated as 28.6 and $56.2 \%$, respectively. The average uncertainties estimated in this study were within the uncertainty ranges of $\mathrm{eBC}_{\mathrm{ff}}(50 \%-96 \%)$ and $\mathrm{eBC}$ wb $(4 \%-50 \%)$ reported by Favez et al. $(2010)^{17}$. Compared to Martinsson et al. $(2017)^{41}$, the uncertainty of $\mathrm{eBC}_{\mathrm{ff}}$ in this study was lower than it $(41 \%)$ and the uncertainty of $\mathrm{eBC}_{\mathrm{wb}}$ was higher than that study (42\%). Despite the high uncertainties, $\mathrm{eBC}_{\mathrm{ff}}$ and $\mathrm{eBC} \mathrm{wb}_{\mathrm{wb}}$ calculated with the optimal a combination in the hourly resolution were well correlated with $\mathrm{NO}_{2}$ and $\mathrm{K}_{\mathrm{wb}}^{+}$, respectively (Fig. 4). It suggested that the use of $\mathrm{K}_{\mathrm{wb}}^{+}$to optimize the a combination in the Aethalometer model can accurately estimate the $\mathrm{BC}$ from fossil fuel combustion and wood burning.

\section{DISCUSSIONS}

The Aethalometer model is originally developed to attribute $B C$ into liquid fossil fuel combustion (vehicle emissions) and biomass/ wood burning in western Europe ${ }^{16}$. In other places, where coal combustion is an important source of $\mathrm{BC}$, the application of the Aethalometer model would overestimate the contribution of liquid fossil fuel combustion assuming $B C$ is only from liquid fossil fuel combustion and wood burning. For instance, vehicle emissions, coal combustion, and biomass burning contributed 31,45 , and $24 \%$ to EC during winter in Xi'an China with ${ }^{14} \mathrm{C}$ and stable isotope $\left({ }^{13} \mathrm{C}\right)^{70}$. Therefore, $\mathrm{BC}$ sources attributed by the Aethalometer model should be adjusted to fossil fuel (liquid + solid) combustion and wood/biomass burning in China and other places with large coal consumption. For instance, a study conducted in Xiamen, China suggested that the average contributions of $\mathrm{BC}$ from fossil fuel combustion and biomass burning derived by the source-originated model were 67.4 and $32.6 \%$, respectively. They were very close to the results $(66.7 \%$ for $\mathrm{eBC}_{\mathrm{ff}}$ and $33.3 \%$ for $\mathrm{eBC}_{\mathrm{wb}}$ ) obtained by the Aethalometer model $^{71}$. The intercomparison results suggested that it was reasonable to attribute $B C$ into fossil fuel combustion and wood/biomass burning using the Aethalometer model in China.

The optimal $a_{\mathrm{ff}}$ obtained with $\mathrm{K}_{\mathrm{wb}}^{+}$also implied the reasonability to attribute $\mathrm{BC}$ into fossil fuel combustion rather than liquid fossil fuel combustion. The $a$ for solid fossil fuel combustion was generally higher than that for liquid fossil fuel combustion, although the $a$ value was determined by combustion efficiency ${ }^{33}$ and fuel types (Supplementary Table 2). If fossil fuel combustionrelated $B C$ was only from liquid fossil fuel combustion, the optimal $a_{\mathrm{ff}}$ in this study should be within the ranges of reported $a$ values for liquid fossil fuel combustion (i.e., as $0.91 \pm 0.08$ from Supplementary Table 2). However, the derived optimal $a_{\mathrm{ff}}$ values in this study (1.02-1.19) were higher than the reported $a$ ranges for liquid fossil fuel, but lower than that from solid fossil fuel combustion. It suggested that the additional sources of BC like 
coal combustion. Therefore, the derived $a_{\mathrm{ff}}$ suggested that the $\mathrm{eBC}_{\mathrm{ff}}$ resolved by the Aethalometer model contained the contributions from both the liquid and solid fossil fuel combustion-related BC. It also raised a question that how to further separate the fossil fuel combustion-related BC into liquid and solid fossil fuel using the Aethalometer model.

Although the dust and sea salt originated potassium was subtracted from the measured potassium $\left(\mathrm{K}_{\mathrm{wb}}^{+}\right.$accounting for $93.6 \pm 6.68 \%$ of the measured $\mathrm{K}^{+}$), the usage of $\mathrm{K}_{\mathrm{wb}}^{+}$as a wood burning tracer to optimize the $a$ values had several issues. For instance, the highest Pearson correlation between $\mathrm{K}_{\mathrm{wb}}^{+}$and $\mathrm{eBC}_{\mathrm{wb}}$ in this study $\left(r^{2}=0.66\right)$ was lower than that between LG and $\mathrm{eBC}_{\mathrm{wb}}\left(r^{2}=0.91\right)^{21}$ assuming an $a_{\mathrm{ff}}$ of 0.80 . Using the least squared method $^{38}$ to solve the fitting between $\mathrm{K}_{\mathrm{wb}}^{+} / \mathrm{EC}$ and $b_{\text {abs_370/ }}$

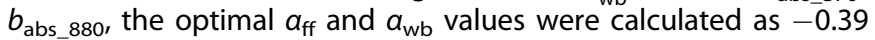
and 1.96, respectively in this study. The solved $a_{w b}$ seems plausible while the $a_{\mathrm{ff}}$ was much lower than the reported $a$ for fossil fuel combustion as discussed above. Anyway, the dynamic constraint using hourly measured potassium improved the BC source apportionment results compared to the fixed $a$ values. Further researches should focus on the use of radiocarbon or LG to get the site-specific optimal $a$ values prior to BC source apportionment with the Aethalometer model in China. Furthermore, the methodology should be developed to apportion the BC into vehicle emissions, coal combustion, and biomass burning using the optical method with the help of ${ }^{14} \mathrm{C}$ and ${ }^{13} \mathrm{C}$.

\section{METHODS}

\section{Observation data}

Near real-time ( $1 \mathrm{~h}$ resolution) ambient light absorption coefficients $\left(b_{\mathrm{abs}}\right)$, water-soluble ions, OC, and EC from March 2018 to February 2019 were measured at a supersite of Wuhan, Central China (Supplementary Fig. 5). Ambient light absorption coefficients at seven wavelengths $(370,470,520$, $590,660,880$, and $950 \mathrm{~nm}$ ) were continuously measured using an Aethalometer (AE31, Magee Scientific, USA) equipped with a $\mathrm{PM}_{2.5}$ inlet. Simultaneous measurements of $\mathrm{OC}$ and $\mathrm{EC}$ in $\mathrm{PM}_{2.5}$ were conducted with a semicontinuous thermal-optical transmittance carbon analyser (Sunset RT4 , USA) using a simplified version of the NIOSH 5040 protocol $^{72}$. Detailed information about OC/EC measurements can be found in Supplementary Table 3, Supplementary Fig. 6, and Supplementary Methods. Hourly watersoluble ions including $\mathrm{NH}_{4}^{+}, \mathrm{Na}^{+}, \mathrm{Mg}^{2+}, \mathrm{K}^{+}, \mathrm{Ca}^{2+}, \mathrm{Cl}^{-}, \mathrm{NO}_{3}^{-}$, and $\mathrm{SO}_{4}^{2-}$ were measured using an online ion chromatography analyser (MARGA-1S, Metrohm) equipped with a $\mathrm{PM}_{2.5}$ inlet (Supplementary Methods). The scatter plot between the total anions and cations during the entire period showed a high correlation with $r^{2}$ of 0.95 and slope close to 1, indicating the good quality of the dataset (Supplementary Fig. 7). On-site meteorological parameters during the observational period were synchronously recorded (Supplementary Fig. 8).

\section{AE 31 data correction}

$B C$ concentration measured by $A E 31$ is determined by the light absorption $\left(b_{\mathrm{abs}}\right)$ and the mass absorption cross section (MAC) and it is reported as $\mathrm{eBC}^{73}$. Due to the loading and multiple scattering effects, the $b_{\mathrm{abs}}$ of aerosol deposited on the filter was different from the ambient air. A method developed by Weingartner et al. (2003) $)^{74}$ was used to correct the $b_{\text {abs }}$ (more details can be found in Supplementary Methods). The MAC is determined by the particle size, mixing state of aerosol components, and morphology $1,28,75$ and it shows spatial heterogeneity (Supplementary Methods). To determine the local MAC, the linear regression between the corrected $b_{\text {abs }}$ and EC mass concentration was conducted (Supplementary Fig. 9) and it showed temporal variations (Supplementary Fig. 10). After the correction of $b_{\mathrm{abs}}$ and MAC, the eBC level was calculated as the ratio of $b_{\mathrm{abs}}$ to MAC. The $a$ of ambient aerosol was calculated using a power-law fitting with the absorption coefficients at seven wavelengths ${ }^{1,22,27}$ and denoted as $a_{370 \_950}$ in this study.

\section{Wood burning derived potassium $\left(\mathrm{K}_{w b}^{+}\right)$}

In this study, potassium from wood burning was corrected by the following equation, considering sodium and calcium as the tracers of sea salt and dust, respectively ${ }^{19}$ :

$\mathrm{K}_{\mathrm{wb}}^{+}=\left(\mathrm{K}_{\mathrm{m}}^{+}-0.036 \times \mathrm{Na}_{\mathrm{m}}^{+}-\left[\mathrm{K}^{+} / \mathrm{Ca}^{2+}\right]_{\text {dust }} \times \mathrm{Ca}_{\mathrm{nss}}^{2+}\right) /\left(1-0.1 \times\left[\mathrm{K}^{+} / \mathrm{Ca}^{2+}\right]_{\text {dust }}\right)$

where $\mathrm{K}_{\mathrm{wb}}^{+}$is the wood burning derived $\mathrm{K}^{+} ; \mathrm{K}^{+}{ }_{\mathrm{m}}$ and $\mathrm{Na}^{+}{ }_{\mathrm{m}}$ represent the measured ambient mass concentrations of $\mathrm{K}^{+}$and $\mathrm{Na}^{+}$, respectively; 0.036 is the standard ratio of $\mathrm{K}^{+} / \mathrm{Na}^{+}$in sea salt ${ }^{76} ;\left[\mathrm{K}^{+} / \mathrm{Ca}^{2+}\right]_{\text {dust }}$ is the ratio of potassium to calcium in local dust $(0.053$ in this study, see Supplementary Methods and Supplementary Fig. 11). $\mathrm{Ca}_{\text {nss }}^{2+}$ is the non-sea salt $\mathrm{Ca}^{2+}$ concentration in the ambient air corrected by that from sea salt ${ }^{19}$. After the correction, the statistical robust correlation between $\mathrm{K}_{\mathrm{wb}}^{+}$ and EC showed that $\mathrm{K}_{\mathrm{wb}}^{+}$was a good indicator of wood burning (Supplementary Methods).

\section{Aethalometer model}

With the light absorption and $a$ values to apportion the eBC into fossil fuel combustion and wood burning, the Aethalometer model can be expressed as follows ${ }^{38}$ :

$$
\begin{aligned}
& b_{\mathrm{abs}}\left(\lambda_{1}\right)_{\mathrm{ff}} / b_{\mathrm{abs}}\left(\lambda_{2}\right)_{\mathrm{ff}}=\left(\lambda_{1} / \lambda_{2}\right)^{-a_{\mathrm{ff}}} \\
& b_{\mathrm{abs}}\left(\lambda_{1}\right)_{\mathrm{wb}} / b_{\mathrm{abs}}\left(\lambda_{2}\right)_{\mathrm{wb}}=\left(\lambda_{1} / \lambda_{2}\right)^{-a_{\mathrm{wb}}} \\
& b_{\mathrm{abs}}(\lambda)=b_{\mathrm{abs}}(\lambda)_{\mathrm{ff}}+b_{\mathrm{abs}}(\lambda)_{\mathrm{wb}} \\
& \mathrm{eBC} C_{\mathrm{wb}}=\frac{\frac{b_{\mathrm{abs}}\left(\lambda_{1}\right)-b_{\mathrm{abs}}\left(\lambda_{2}\right) \times\left(\lambda_{1} / \lambda_{2}\right)^{-a_{\mathrm{ff}}}}{\left(\lambda_{1} / \lambda_{2}\right)^{-a_{\mathrm{wb}}}-\left(\lambda_{1} / \lambda_{2}\right)^{-a_{\mathrm{ff}}}}}{b_{\mathrm{abs}}\left(\lambda_{2}\right)} \times \mathrm{eBC}
\end{aligned}
$$

where $\lambda_{1}$ and $\lambda_{2}$ are the wavelengths near-ultraviolet and near-infrared, respectively; $a_{\mathrm{ff}}$ and $a_{\mathrm{wb}}$ are the absorption Angström exponent for fossil fuel combustion and wood burning, respectively. Combined the Eq. (2)-(4), the mass concentration of $\mathrm{eBC}_{\mathrm{wb}}$ can be calculated with Eq. (5).

\section{Sensitivity analysis}

The simultaneous measurements of $\mathrm{K}_{\mathrm{wb}}^{+}$and eBC provided the potential to conduct the sensitive analysis of $a$ on the Aethalometer model result. It is expected that the intercept of the linear regression between $e B C_{w b}$ and $\mathrm{K}_{\mathrm{wb}}^{+}$should be zero if $\mathrm{eBC} \mathrm{wb}_{\mathrm{wb}}$ and $\mathrm{K}_{\mathrm{wb}}^{+}$are only from the wood burning and they have the same atmospheric removal rates ${ }^{20,21,42}$. In practice, the intercept of the linear regression between $\mathrm{eBC}_{\mathrm{wb}}$ and $\mathrm{K}_{\mathrm{wb}}^{+}$can approach zero by changing the $a_{\mathrm{ff}}$ and $a_{\mathrm{wb}}$ in the calculation of $\mathrm{eBC} C_{\mathrm{wb}}$. The combination of $a_{\mathrm{ff}}$ and $a_{\mathrm{wb}}$ which resulted in the zero or approaching zero of the intercept was considered as the optimal $a$ values $20,21,42$. To calculate the $\mathrm{eBC} \mathrm{wb}_{\mathrm{wb}}$, the variation step was set as 0.01 for $a_{\mathrm{ff}}$ and $a_{\mathrm{wb}}$, which varied in the ranges of $0.80-1.30$ and $1.60-2.20$, respectively. The Pearson correlation coefficient, slope, intercept, normalized mean bias (NMB), root mean squared error (RMSE), and index of agreement (IOA) (Supplementary Methods) of the linear regression between $\mathrm{eB}_{\mathrm{wb}}$ and $\mathrm{K}_{\mathrm{wb}}^{+}$were calculated to find the optimal a combination.

\section{DATA AVAILABILITY}

Data are available on request from the corresponding author (kongshaofei@cug.edu.cn).

Received: 9 January 2021; Accepted: 30 July 2021;

Published online: 17 August 2021

\section{REFERENCES}

1. Bond, T. C. et al. Bounding the role of black carbon in the climate system: a scientific assessment. J. Geophys. Res. Atmos. 118, 5380-5552 (2013).

2. Jacobson, M. Z. Strong radiative heating due to the mixing state of black carbon in atmospheric aerosols. Nature 409, 695-697 (2001).

3. Ramanathan, V. \& Carmichael, G. Global and regional climate changes due to black carbon. Nat. Geosci. 1, 221-227 (2008).

4. Li, B. et al. The contribution of China's emissions to global climate forcing. Nature 531, 357-361 (2016).

5. Ding, A. J. et al. Enhanced haze pollution by black carbon in megacities in China. Geophys. Res. Lett. 43, 2873-2879 (2016).

6. Wang, Z., Huang, X. \& Ding, A. Dome effect of black carbon and its key influencing factors: a one-dimensional modelling study. Atmos. Chem. Phys. 18, 2821-2834 (2018). 
7. Mordukhovich, Irina et al. Black carbon exposure, oxidative stress genes, and blood pressure in a repeated-measures study. Environ. Health Pesp. 117, 1767-1772 (2009).

8. Bové, $\mathrm{H}$. et al. Ambient black carbon particles reach the fetal side of human placenta. Nat. Commun. 10, 1-7 (2019).

9. Ljungman, P. L. S. et al. Long-term exposure to particulate air pollution, black carbon, and their source components in relation to ischemic heart disease and stroke. Environ. Health Perspect. 127, 107012 (2019).

10. Cape, J. N., Coyle, M. \& Dumitrean, P. The atmospheric lifetime of black carbon. Atmos. Environ. 59, 256-263 (2012).

11. Liu, D., He, C., Schwarz, J. P. \& Wang, X. Lifecycle of light-absorbing carbonaceous aerosols in the atmosphere. npj Clim. Atmos. Sci. 3, 40 (2020).

12. Lund, M. T. et al. Short black carbon lifetime inferred from a global set of aircraft observations. npj Clim. Atmos. Sci. 1, 31 (2018).

13. Jacobson, M. Z. Short-term effects of controlling fossil-fuel soot, biofuel soot and gases, and methane on climate, Arctic ice, and air pollution health. J. Geophys. Res. Atmos. 115, D14209 (2010).

14. Peng, J. et al. Markedly enhanced absorption and direct radiative forcing of black carbon under polluted urban environments. Proc. Natl. Acad. Sci. USA. 113, 4266-4271 (2016).

15. Briggs, N. L. \& Long, C. M. Critical review of black carbon and elemental carbon source apportionment in Europe and the United States. Atmos. Environ. 144, 409-427 (2016).

16. Sandradewi, J. et al. Using aerosol light absorption measurements for the quantitative determination of wood burning and traffic emission contributions to particulate matter. Environ. Sci. Technol. 42, 3316-3323 (2008).

17. Favez, O. et al. Inter-comparison of source apportionment models for the estimation of wood burning aerosols during wintertime in an Alpine city (Grenoble, France). Atmos. Chem. Phys. 10, 5295-5314 (2010)

18. Herich, H., Hueglin, C. \& Buchmann, B. A 2.5 year's source apportionment study of black carbon from wood burning and fossil fuel combustion at urban and rural sites in Switzerland. Atmos. Meas. Tech. 4, 1409-1420 (2011).

19. Harrison, R. M., Beddows, D. C. S., Hu, L. \& Yin, J. Comparison of methods for evaluation of wood smoke and estimation of UK ambient concentrations. Atmos. Chem. Phys. 12, 8271-8283 (2012)

20. Fuller, G. W., Tremper, A. H., Baker, T. D., Yttri, K. E. \& Butterfield, D. Contribution of wood burning to $\mathrm{PM}_{10}$ in London. Atmos. Environ. 87, 87-94 (2014).

21. Helin, A. et al. Characteristics and source apportionment of black carbon in the Helsinki metropolitan area, Finland. Atmos. Environ. 190, 87-98 (2018).

22. Zheng, H. et al. A 5.5-year observations of black carbon aerosol at a megacity in Central China: levels, sources, and variation trends. Atmos. Environ. 232, 117581 (2020).

23. Healy, R. M. et al. Ambient measurements and source apportionment of fossil fue and biomass burning black carbon in Ontario. Atmos. Environ. 161, 34-47 (2017).

24. Kalogridis, A. C. et al. Assessment of wood burning versus fossil fuel contribution to wintertime black carbon and carbon monoxide concentrations in Athens, Greece. Atmos. Chem. Phys. 18, 10219-10236 (2018).

25. Liu, Y., Yan, C. \& Zheng, M. Source apportionment of black carbon during winter in Beijing. Sci. Total Environ. 618, 531-541 (2018).

26. Singh, S. et al. Ambient black carbon particulate matter in the coal region of Dhanbad, India. Sci. Total Environ. 615, 955-963 (2018).

27. Zheng, H. et al. Intra-regional transport of black carbon between the south edge of the North China Plain and central China during winter haze episodes. Atmos. Chem. Phys. 19, 4499-4516 (2019).

28. Bond, T. C. \& Bergstrom, R. W. Light absorption by carbonaceous particles: an investigative review. Aerosol Sci. Tech. 40, 27-67 (2006).

29. Blanco-Alegre, C. et al. Aethalometer measurements in a road tunnel: a step forward in the characterization of black carbon emissions from traffic. Sci. Total Environ. 703, 135483 (2020).

30. Kirchstetter, T. W., Novakov, T. \& Hobbs, P. V. Evidence that the spectral dependence of light absorption by aerosols is affected by organic carbon. $J$. Geophys. Res. Atmos. 109, D21208 (2004).

31. Reid, J. S. et al. A review of biomass burning emissions part III: intensive optical properties of biomass burning particles. Atmos. Chem. Phys. 5, 827-849 (2005).

32. Lewis, K., Arnott, W. P., Moosmüller, H. \& Wold, C. E. Strong spectral variation of biomass smoke light absorption and single scattering albedo observed with a novel dual-wavelength photoacoustic instrument. J. Geophys. Res. Atmos. 113 D16203 (2008)

33. McClure, C. D., Lim, C. Y., Hagan, D. H., Kroll, J. H. \& Cappa, C. D. Biomass-burningderived particles from a wide variety of fuels - Part 1: properties of primary particles. Atmos. Chem. Phys. 20, 1531-1547 (2020).

34. Lack, D. A. \& Cappa, C. D. Impact of brown and clear carbon on light absorption enhancement, single scatter albedo and absorption wavelength dependence of black carbon. Atmos. Chem. Phys. 10, 4207-4220 (2010).
35. Wu, C., Wu, D. \& Yu, J. Z. Quantifying black carbon light absorption enhancement with a novel statistical approach. Atmos. Chem. Phys. 18, 289-309 (2018).

36. Liu, C., Chung, C. E., Yin, Y. \& Schnaiter, M. The absorption Ångström exponent of black carbon: from numerical aspects. Atmos. Chem. Phys. 18, 6259-6273 (2018).

37. You, R., Radney, J. G., Zachariah, M. R. \& Zangmeister, C. D. Measured wavelengthdependent absorption enhancement of internally mixed black carbon with absorbing and nonabsorbing materials. Environ. Sci. Technol. 50, 7982-7990 (2016).

38. Zotter, P. et al. Evaluation of the absorption Ångström exponents for traffic and wood burning in the Aethalometer-based source apportionment using radiocarbon measurements of ambient aerosol. Atmos. Chem. Phys. 17, 4229-4249 (2017).

39. Mousavi, A. et al. Source apportionment of black carbon (BC) from fossil fuel and biomass burning in metropolitan Milan, Italy. Atmos. Environ. 203, 252-261 (2019).

40. Becerril-Valle, M. et al. Characterization of atmospheric black carbon and copollutants in urban and rural areas of Spain. Atmos. Environ. 169, 36-53 (2017).

41. Martinsson, J. et al. Carbonaceous aerosol source apportionment using the Aethalometer model - evaluation by radiocarbon and levoglucosan analysis at a rural background site in southern Sweden. Atmos. Chem. Phys. 17, 4265-4281 (2017).

42. Titos, G. et al. Spatial and temporal variability of carbonaceous aerosols: assessing the impact of biomass burning in the urban environment. Sci. Total Environ. 578, 613-625 (2017).

43. Heal, M. R. The application of carbon-14 analyses to the source apportionment of atmospheric carbonaceous particulate matter: a review. Anal. Bioanal. Chem. 406, 81-98 (2014).

44. Hoffmann, D., Tilgner, A., linuma, Y. \& Herrmann, H. Atmospheric stability of levoglucosan: a detailed laboratory and modeling study. Environ. Sci. Technol. 44 694-699 (2010)

45. Lai, C., Liu, Y., Ma, J., Ma, Q. \& He, H. Degradation kinetics of levoglucosan initiated by hydroxyl radical under different environmental conditions. Atmos. Environ. 91 32-39 (2014).

46. Gensch, I. et al. Using $\delta^{13} \mathrm{C}$ of levoglucosan as a chemical clock. Environ. Sci. Technol. 52, 11094-11101 (2018).

47. Fabbri, D. et al. Levoglucosan and other cellulose and lignin markers in emissions from burning of Miocene lignites. Atmos. Environ. 43, 2286-2295 (2009).

48. Yan, C. et al. Residential coal combustion as a source of levoglucosan in China Environ. Sci. Technol. 52, 1665-1674 (2018).

49. Zhao, Y., Hu, M., Slanina, S. \& Zhang, Y. Chemical compositions of fine particulate organic matter emitted from Chinese cooking. Environ. Sci. Technol. 41, 99-105 (2007).

50. Christian, T. J., Yokelson, R. J., Cardenas, B., Molina, L. T. \& Engling, G. Trace gas and particle emissions from domestic and industrial biofuel use and garbage burning in central Mexico. Atmos. Chem. Phys. 10, 565-584 (2010).

51. Bhattarai, $\mathrm{H}$. et al. Levoglucosan as a tracer of biomass burning: recent progress and perspectives. Atmos. Res. 220, 20-33 (2019).

52. Chen, J. et al. A review of biomass burning: emissions and impacts on air quality, health and climate in China. Sci. Total Environ. 579, 1000-1034 (2017).

53. Sun, J. et al. Characterization of $P_{2.5}$ source profiles from typical biomass burning of maize straw, wheat straw, wood branch, and their processed products (briquette and charcoal) in China. Atmos. Environ. 205, 36-45 (2019).

54. Zheng, $\mathrm{H}$. et al. The impacts of pollution control measures on $\mathrm{PM}_{25}$ reduction: insights of chemical composition, source variation and health risk. Atmos. Environ. 197, 103-117 (2019).

55. Zheng, M. et al. Initial cost barrier of ammonia control in Central China. Geophys. Res. Lett. 46, 14175-14184 (2019).

56. Zheng, $\mathrm{H}$. et al. Significant changes in the chemical compositions and sources of $\mathrm{PM}_{2.5}$ in Wuhan since the city lockdown as COVID-19. Sci. Total Environ. 739, 140000 (2020).

57. Wu, C., Wu, D. \& Yu, J. Z. Estimation and uncertainty analysis of secondary organic carbon using 1 year of hourly organic and elemental carbon data. J. Geophys. Res. Atmos. 124, 2774-2795 (2019).

58. Petzold, A. et al. Recommendations for reporting "black carbon" measurements. Atmos. Chem. Phys. 13, 8365-8379 (2013).

59. Weingartner, E. et al. Absorption of light by soot particles: determination of the absorption coefficient by means of aethalometers. J. Aerosol Sci. 34, 1445-1463 (2003).

60. Zanatta, M. et al. A European aerosol phenomenology-5: climatology of black carbon optical properties at 9 regional background sites across Europe. Atmos. Environ. 145, 346-364 (2016).

61. Pio, C. A. et al. Climatology of aerosol composition (organic versus inorganic) at nonurban sites on a west-east transect across Europe. J. Geophys. Res. Atmos. 112 1-15 (2007). 
62. Hoffer, A. et al. Optical properties of humic-like substances (HULIS) in biomassburning aerosols. Atmos. Chem. Phys. 6, 3563-3570 (2006).

63. Lack, D. A., Bahreini, R., Langridge, J. M., Gilman, J. B. \& Middlebrook, A. M. Brown carbon absorption linked to organic mass tracers in biomass burning particles. Atmos. Chem. Phys. 13, 2415-2422 (2013).

64. Liu, S. et al. Enhanced light absorption by mixed source black and brown carbon particles in UK winter. Nat. Commun. 6, 8435 (2015).

65. Harrison, R. M. et al. An evaluation of some issues regarding the use of aethalometers to measure wood smoke concentrations. Atmos. Environ. 80, 540-548 (2013).

66. Dumka, U. C. et al. Assessment of biomass burning and fossil fuel contribution to black carbon concentrations in Delhi during winter. Atmos. Environ. 194, 93-109 (2018).

67. Taylor, K. E. Summarizing multiple aspects of model performance in a single diagram. J. Geophys. Res. 106, 7183-7192 (2001).

68. Carslaw, D. C. \& Ropkins, K. openair - An R package for air quality data analysis. Environ. Modell. Softw. 27-28, 52-61 (2012).

69. Saleh, R. et al. Absorptivity of brown carbon in fresh and photo-chemically aged biomass-burning emissions. Atmos. Chem. Phys. 13, 7683-7693 (2013).

70. Utry, N. et al. Correlations between absorption Angström exponent (AAE) of wintertime ambient urban aerosol and its physical and chemical properties. Atmos. Environ. 91, 52-59 (2014).

71. Williams, M. A., Kumar, T. V. L. \& Rao, D. N. Characterizing black carbon aerosols in relation to atmospheric boundary layer height during wet removal processes over a semi urban location. J. Atmos. Sol. Ter. Phy. 182, 165-176 (2019).

72. Liakakou, E. et al. Long-term variability, source apportionment and spectral properties of black carbon at an urban background site in Athens, Greece. Atmos. Environ. 222, 117137 (2020).

73. Wallace, L. Real-time measurements of black carbon indoors and outdoors: a comparison of the photoelectric aerosol sensor and the Aethalometer. Aerosol Sci. Tech. 39, 1015-1025 (2005).

74. Bauer, J. J., Yu, X. Y., Cary, R., Laulainen, N. \& Berkowitz, C. Characterization of the sunset semi-continuous carbon aerosol analyzer. J. Air Waste Mange. 59, 826-833 (2009).

75. Ni, H. et al. Source apportionment of carbonaceous aerosols in Xi'an, China: insights from a full year of measurements of radiocarbon and the stable isotope ${ }^{13}$ C. Atmos. Chem. Phys. 18, 16363-16383 (2018).

76. Deng, J. et al. Source apportionment of black carbon aerosols from light absorption observation and source-oriented modeling: an implication in a coastal city in China. Atmos. Chem. Phys. 20, 14419-14435 (2020).

\section{ACKNOWLEDGEMENTS}

This study was financially supported by the Key Program of the Ministry of Science and Technology of the People's Republic of China (2016YFA0602002 and 2017YFC0212602), the National Natural Science Foundation of China (41830965; 42077202), the Key Program for Technical Innovation of Hubei Province
(2017ACA089). The project was also supported by the Fundamental Research Funds for the National Universities, China University of Geosciences (Wuhan) (G1323519230; 201616; 26420180020; and CUG190609), and the Start-up Foundation for Advanced Talents, China University of Geosciences (Wuhan) (162301182756).

\section{AUTHOR CONTRIBUTIONS}

H.Z. and S.K. proposed the study and wrote the manuscript; S.K. reviewed and edited the manuscript; N. C. provided the dataset; Z.F., Y.Z., L.Y., Y.C., and S.Z. helped the data analysis; Y.Y., D.L., D.Z., C.L., T.Z., J.G., and S.Q. edited the manuscript. All authors contributed to the discussions and revisions.

\section{COMPETING INTERESTS}

The authors declare no competing interests.

\section{ADDITIONAL INFORMATION}

Supplementary information The online version contains supplementary material available at https://doi.org/10.1038/s41612-021-00200-y.

Correspondence and requests for materials should be addressed to S.K.

Reprints and permission information is available at http://www.nature.com/ reprints

Publisher's note Springer Nature remains neutral with regard to jurisdictional claims in published maps and institutional affiliations.

c) (P)

Open Access This article is licensed under a Creative Commons Attribution 4.0 International License, which permits use, sharing, adaptation, distribution and reproduction in any medium or format, as long as you give appropriate credit to the original author(s) and the source, provide a link to the Creative Commons license, and indicate if changes were made. The images or other third party material in this article are included in the article's Creative Commons license, unless indicated otherwise in a credit line to the material. If material is not included in the article's Creative Commons license and your intended use is not permitted by statutory regulation or exceeds the permitted use, you will need to obtain permission directly from the copyright holder. To view a copy of this license, visit http://creativecommons. org/licenses/by/4.0/.

(c) The Author(s) 2021 